\title{
FUENTES, FECHAS, ORDEN Y SENTIDO DEL LIBRO I DE LAS OBRAS DE BOSCÁN
}

BIENVENIDO MORRos MESTRES

Universidad Autónoma de Barcelona

EL ORIGINAL DE IMPRENTA, EL MANUSCRITO LASTANOSA-GAYANGOS Y LA EDICIÓN DE 1543

Cuando el 23 de marzo de 1542 Boscán se compromete a entregar el original de imprenta de sus poemas, y los de Garcilaso, a su editor Joan Bages, ya debía tenerlo copiado y preparado, porque sólo cuatro días después, con formato incluido («de forma de quart de full» ${ }^{1}$ ), está ya en poder del impresor, Carlos y Joan Amorós, quienes a su vez se comprometen a seguir un ritmo de trabajo que seguramente no pudieron cumplir, y que debía empezar «del primer del mes de abril» de ese mismo año (ibíd.). Los Amorós habían asegurado poder componer dos formas por día, el equivalente a un cuaderno, cuyo formato era un cuarto de a dos o cuarto en octavos, y ésa era una tarea perfectamente asequible, si no se simultaneaba con otras, porque los talleres de imprenta podían llegar a imprimir un pliego y medio diario, como, por ejemplo, se hizo en el taller de Juan de la Cuesta que sacó la princeps del Quijote ${ }^{2}$.

El original de imprenta, copiado por él mismo o mandado a copiar a un profesional, que Boscán pudo haber hecho llegar a su editor entre el 23 y el 27 de marzo de 1542 no era el manuscrito Lastanosa-Gayangos (conocido con la sigla $L$ ), porque había de incluir por fuerza textos que no se habían copiado en él y porque había descartado otros que sí aparecían en el códice en cuestión. Era, pues, un original de imprenta en que Boscán ofrecía la última versión y selección de sus poemas en vistas a su publicación, distinta a la que atestigua $L$, unos años anterior, porque reproduce, entre otros, los poemas que el barcelonés había escrito con ocasión de su boda con Ana Girón de Rebolledo en

\footnotetext{
${ }^{1}$ Los contratos están reproducidos en la edición de Carlos Clavería, Obra completa, Madrid, Cátedra, 1999, pág. 552.

2 Véase a ese respecto el valiosísimo libro de F. Rico, El texto de «Quijote». Preliminares a una ecdótica del Siglo de Oro, Barcelona, Destino, 2005, pág. 174.
} 
septiembre de 1539, y porque ofrece, para cada uno de sus libros, una estructura perfectamente definida.

Para la sección de sonetos y canciones, la que configura el libro II de su edición, Boscán en $L$ no copia los primeros onces sonetos ni los últimos veinticinco. Entre los sonetos finales, se hallan unos cuantos, alrededor de quince, sin duda compuestos para narrar el amor conyugal, esto es, después de septiembre de 1539, y otros, ocho en concreto, que recrean símiles que Ausiàs March había desarrollado en uno de sus poemas más célebres ${ }^{3}$. Para la sección todavía de metros italianos, pero ya no de cancionero petrarquista, la que constituye el libro III del impreso de Amorós, el barcelonés en $L$ no recoge ni la fábula de Leandro y Hero, ni la epístola que le escribe Diego Hurtado de Mendoza, ni la que él le dirige al poeta granadino como respuesta, y si no incluye esos dos últimos poemas es porque los compone mucho después, tras su boda con la dama valenciana («heme casado con una mujer», dice en la epístola) ${ }^{4}$. Si no copia la fábula de Leando y Hero es porque tampoco la ha escrito, ya que debió empezar a hacerlo después de 1537, que es el año en que Bernardo Tasso saca precisamente el Libro terzo de gli Amori, que cierra con una «Favola di Leandro e d'Ero», también inspirada, como reconoce el propio autor en su dedicatoria a Antonia de Cardona, por el epilio de Museo y compuesta en endecasílabos sueltos.

La estrecha relación que nuestro poeta mantuvo con Diego Hurtado de Mendoza es también tardía, y debe remitir al mismo período en que ambos, casi al unísono, decidieron escribir diversos sonetos con los mismos símiles que Ausiàs March introduce en un mismo poema. El barcelonés escribe seis sonetos diferentes para tratar de manera independiente cada uno de esos símiles, mientras Diego Hurtado de Mendoza compone la mitad, tres, correspondientes a las tres primeras estrofas del texto valenciano.

Con todos estos datos, creo que resulta fácil inferir que el manuscrito $L$ representa un estadio de los poemas de Boscán anterior a septiembre de 1539, y que, al recoger buena parte de las obras de Garcilaso, debe ser posterior a la fecha de su muerte, ocurrida en octubre de 1536, que es cuando el barcelonés pudo recibir el manuscrito con los poemas de su amigo, según hace contar el autor del texto dirigido «A los lectores» con que se abre la edición de 1543.

\footnotetext{
3 Para el orden del libro II, véase B. Morros, «El Canzoniere de Boscán (libro II, Barcelona, 1543)», Revista de Filología Española, LXXXV, 2005, págs. 245-270.

${ }^{4}$ Es el argumento que usa C. Clavería para fechar $L$, en «Lastanosa no describe», Hispanic Review, 62, 1994, págs. 53-57.
} 


\section{EL LIBRO I}

La sección equivalente al libro I es muy parecida en $L$ y en la edición de Amorós. Como parte integrante de esa sección hay que descartar los endecasílabos sueltos enderezados a la duquesa de Soma por dos razones muy claras. La primera cabe buscarla en el metro, que no guarda ninguna relación con los octosílabos y tetrasílabos del libro I. La segunda tiene que ver con su destinataria, doña Beatriz Fernández de Figueroa, nieta del Gran Capitán y duquesa de Soma desde 1539 tras su boda con don Fernando Folch de Cardona. A ella Boscán dirige la carta con que prologa el libro II precisamente porque la cree al corriente, por sus orígenes familiares, de la tradición literaria italiana. Por eso carece de sentido que elija un poema en endecasílabos y con una destinataria con esa formación para inaugurar una sección, la menos valorada de sus obras, que representa la tradición más castiza. El poema en cuestión, pues, habría que entenderlo como prólogo a los cuatro libros en que divide el volumen ${ }^{5}$.

Así las cosas, en la edición barcelonesa, el libro I consta de veintisiete poemas, mientras en el manuscrito $L$, el apartado equivalente, de treinta. En $L$ aún no figura el primer poema del impreso, el villancico «si no os hubiera mirado», y recoge, por el final, una serie de poemas de intercambio con el Almirante de Castilla don Fadrique Enríquez. De esos poemas, seis en total, Boscán sólo elige uno para cerrar el libro I de la edición, el que sería el número veintisiete, y parece ésa una selección muy meditada, porque incluso, del poema elegido, suprime sus dos últimas estrofas.

\section{EL ABANDONO DE LA CORTE}

Esos poemas Boscán y don Fadrique hubieron de escribirlos antes del 9 de enero de 1538, que es la fecha en que murió el Almirante, pero es difícil saber con exactitud la fecha de su composición. En el primer poema, don Fadrique reconoce haber regresado a la corte, donde ya no halla a Boscán, a quien pregunta si volverá para convertirse en testigo de su sufrimiento por amor:

Hállaos menos en la corte, Adonde Dios me ha traído; Menos por ser allá ido, menos por vuestro deporte, y me quedan más recelos

\footnotetext{
5 De manera distinta lo entiende A. Armisén, Estudios sobre la lengua poética de Boscán. La edición de 1543, Zaragoza, Universidad de Zaragoza, 1982, págs. 341-346.
} 
de los qu'eran menester,

por tener amor poder

de matarme acá de celos

Y pues vuestra pasión calma,

Por mudar vuestra querella,

Quiero saber si con calma

Volveréis acá, o sin ella.

Que si vos queréis mudaros

Ser de tanto mal testigo,

Si lo sé podré lloraros

Como a verdadero amigo (vv. 73-80)

De hecho, el Almirante pregunta a nuestra poeta por unos amores que tuvo en el pasado en la corte para saber si aún se acuerda de ellos o si, por el contrario, los ha acabado olvidando coincidiendo con su marcha. Si ha ocurrido lo segundo, cree que es porque sus sentimientos no habían sido sinceros, y para semejante afirmación se basa en Petrarca, de quien dice que no llegó a curar las heridas de amor por más que se alejara de Laura (o, para ser más exactos, de sus ojos, clara metáfora del arco con que hiere Cupido):

Que si jay! no fue fingida

La pasión que atormentaba

La pena que'ntonces daba

Ahora verná más crecida.

Que al Petrarca, qu'en amar

Leéis que perdió la vida,

No le curó la herida

El arco por aventar (vv. 8-16)

El Almirante siempre cultivó el verso autóctono y nunca se sintió tentado de escribir poesía en metros italianos, pero conocía la obra de Petrarca, especialmente I trionfi, que traducidos en coplas reales se los dedicó Antonio de Obregón (Logroño, 1512; Sevilla, 1526 y 1532).

Boscán empieza el primer poema con que responde al castellano aludiendo claramente a ese cambio de lugar, pero no queda claro en cuál se halla cuando escribe esos versos, si en la península o fuera de ella:

Otro mundo es el que ando,

Otras tierras y otro cielo,

Donde nunca me desmando

A sólo pedir consuelo,

Puesto que le voy buscando (vv. 1-5)

Avalle-Arce, el que mejor ha estudiado a nuestro Almirante, opina que el barcelonés pudo componerlos desde Viena, a donde había viajado en 1532 para for- 
mar parte de la expedición en socorro de la ciudad contra la amenaza turca ${ }^{6}$. Pero conviene recordar que en el siglo XVI la corte era itinerante, y la imperial de Carlos V se había trasladado a Alemania y los Países Bajos desde junio de 1530 a septiembre de 1532. Como cuenta en su égloga II, Garcilaso viaja, en compañía del duque de Alba, a Ratisbona, para reunirse allí con el ejército del Emperador, quien había llegado a la ciudad alemana el 28 de febrero de $1532^{7}$. Estando, pues, en Ratisbona, unos meses después de esa fecha, el toledano dedica unas coplas a Boscán en que se burla de su habilidad para el baile: las titula «a Boscán, porque estando en Alemania, danzó en unas bodas». Las bodas en cuestión hubieron de celebrarse en julio de 1532, porque los meses anteriores Garcilaso los había pasado confinado en un isla del Danubio, y los posteriores no está claro que se quedara en la ciudad alemana hasta finales de setiembre, o que ya acompañara a principios de agosto al nuevo virrey de Nápoles, don Pedro de Toledo, a la ciudad italiana ${ }^{8}$. En la primavera-verano de 1532, pues, Boscán estaba en la corte imperial instalada en Ratisbona, y no parece que desde ella compusiera un poema para referirse a un nuevo amor concebido en un ambiente que ya no era el de su época anterior.

La respuesta al Amirante debió de escribirla el barcelonés cuando abandonó la corte para regresar a Barcelona y fijar allí su residencia habitual. El 20 de diciembre de 1533 todavía se hallaba en la corte, porque en el privilegio imperial, expedido con esa fecha, para su traducción de El cortesano Carlos I le llamaba «Juan Boscán, criado de nuestra casa» ${ }^{9}$, pero a mediados de julio de 1535 ya no formaba parte del ejército que desembarcó en Puerto Farina, ante

6 J.B. de Avalle-Arce, Cancionero del Almirante don Fadrique Eníquez, Barcelona, Quaderns Crema, 1994, pág. 200.

${ }^{7}$ La incorporación posterior del duque de Alba, junto a otros nobles castellanos y aragoneses, al ejército del Emperador la refiere, entre otros cronistas, fray Prudencio de Sandoval: «Justo es asimismo que se sepa el amor grande que los españoles tienen a su príncipe, porque luego que supieron la venida del Turco, y el aparato de guerra que el Emperador hacía para ir contra él, con ser España una provincia tan apartada de Austria y haber en medio enemigos y mares peligrosos, sin ser llamados y compelidos de nadie se pusieron en orden, vendiendo y empeñando sus haciendas y echándolas en armas y caballos, dejando la dulce patria, mujeres e hijos, y unos por Francia, otros por mar, caminaron a largas jornadas por hallarse en la batalla que el Emperador pensaba dar al turco. Los principales que hallo que fueron son: don Fernando Álvarez de Toledo, duque de Alba...»(445 a).

${ }^{8}$ Garcilaso, acompañando al duque de Alba, llegó a Ratisbona después del 14 de marzo de 1532, pero no sabemos si el Emperador lo dejó entrar en la corte, porque había una orden, dictaminada por la Emperatriz, que se lo prohibía. Si llegó a entrar en Ratisbona, sólo lo hizo para estar unos días en la corte, porque enseguida se le obligó a alejarse de ella «cinco leguas al derredor», y se le desterró a una isla del Danubio, en la que debió de permanecer hasta el 25 de junio de ese año, fecha en que se le permite entrar otra vez en la corte para incorporarse a un nuevo destino. En Ratisbona debió de estar hasta el último día de Julio, que es cuando parece abandonar la ciudad en compañía de don Pedro de Toledo para dirigirse a Nápoles.

${ }^{9}$ Véase Martín de Riquer, Juan Boscán y su cancionero barcelonés, Barcelona, Archivo Histórico-Casa del Arcediano, 1945, pág. 13. 
las ruinas de Cartago, a ocho Kilómetros sólo de La Goleta, cuya fortaleza el Emperador conquistó un mes después, un catorce de julio para ser exactos. Siete días más tarde entraba en la ciudad de Túnez gracias a la ayuda que desde el interior había recibido de doce mil cautivos, y, tras abandonar el proyecto de la invasión de Argel, puso rumbo a Trapani, Sicilia, en cuyo puerto atracó el 21 de agosto.

Garcilaso escribe a Boscán primero desde las ruinas de Cartago y después desde Trapani para hablarle de su nuevo amor, pero sobre todo para envidiarle su vida retirada en Barcelona en compañía de una mujer a quien no identifica pero que no puede ser otra que Ana Girón de Rebolledo, con quien el barcelonés debió tener un largo noviazgo:

Tú, que en la patria, entre quien bien te quiere,

La deleitosa playa estás mirando

Y oyendo el son del mar que en ella hiere,

Y sin impedimento contemplando

La misma a quien tú vas eterna fama

En tus vivos escritos procurando,

Alégrate, que más hermosa llama

Que aquella que'l troyano encendimiento

Pudo causar el corazón t’inflama (Elegía II, vv. 145-153)

Hay que recordar que el Emperador inició la campaña africana un 30 de mayo de 1535 desde Barcelona, donde quedaría Boscán acompañado por su futura esposa. A su ciudad natal habría regresado el barcelonés antes de esa fecha y después de diciembre de 1533, que es el período en que conviene situar su polémica con el Almirante de Castilla. En el último de los poemas que le dirigió, copiado en el manuscrito $L$, Boscán presenta a su oponente inmerso en un pleito en que la sentencia no le ha sido favorable:

Cuanto más que os han ganado

Ese pleito, y vos tras eso,

Viendo que sois condenado, añadís en el proceso.

Pues no digáis que os juzgaron

Así por ser en ausencia,

Porque al dar de la sentencia,

Yo sé bien que os condenaron,

Señor, en vuestra presencia.

La sentencia no fue larga,

De justa no sobró nada,

A la persona cargada

Viene medida la carga.

Con todo, es cosa despanto

Questa burla tanto dure; 
Un señor que pudo tanto,

Pues nunca pudo, no cure

Sino de hablar como un santo (vv. 19-35)

En las dos primeras coplas parece referirse a otras en que don Fadrique le lanzaba dardos, seguramente insistiendo en la misma cuestión de los amores cortesanos, pero que marraba por falta de salud o vigor (el Almirante en esa época tendría setenta y cuatro años). Acto seguido el barcelonés le aconseja que dirija su atención hacia su propia persona, pensando en el pleito que convierte en tema del resto del poema. ¿A qué pleito se refiere? ¿Al que mantiene con él a propósito de su condición mudable? ¿O algún pleito que protagonizó el Almirante en vida? Es verdad que el catalán y el castellano disputan sobre cuál de ellos es más constante en el amor, pero no lo hacen en forma de pleito en el que jueces más o menos imparciales puedan otorgar la razón a uno de los dos. Es más probable que el primero aluda a algún pleito real en que el segundo participó por una cuestión similar.

\section{El Pleito del Almirante de Castilla}

El Almirante de Castilla tuvo que hacer frente a diversos pleitos en el tramo final de su vida, cuando ya llevaba bastante tiempo viudo ${ }^{10}$. El primero de ellos duró desde 1532 hasta 1535 y se suscitó por el doble desposorio del conde de Ureña, don Juan Téllez Girón, primo hermano del Almirante. El conde en cuestión se había desposado «en persona por palabras de presente» con doña María de la Cueva, hermana del duque de Alburquerque, pero, al parecer, ya antes había hecho lo mismo con doña María Enríquez, sobrina del Almirante. Don Fadrique informó a la Emperatriz (el Emperador estaba en Alemania) del primer compromiso que había adquirido el conde de Ureña con su sobrina, y que designase un «juez eclesiástico» para poder determinar cuál de los dos matrimonios era el válido. En marzo de 1535, antes de que el Emperador comenzara su campaña africana, los jueces, don Fernando de Valdés, obispo de Oviedo, y el licenciado Hernando Niño, del consejo de la Inquisición, «sentenciaron a favor de doña María de la Cueva, y pronunciaron quel Conde era su marido y mandaronle que se casase con ella» ${ }^{11}$. El Almirante, con esta sentencia, «quedó mal satisfecho y descontento» (ibíd.), y negoció el casamiento de su sobrina, la agraviada en el pleito, con el marqués de Cuellar, don Francisco Fer-

${ }^{10}$ Una amplia relación de esos dos pleitos ofrece J. B. de Avalle-Arce, Cancionero..., págs. 159-168.

${ }^{11}$ Pedro Girón, Crónica del Emperador Carlos V, ed. Juan Sánchez Montes, con prólogo de Peter Rasow, Madrid, Consejo Superior de Investigaciones científicas, 1965, pág. 54. 
nández de la Cueva, pero no le satisfizo la dote que le ofrecían a la novia, por lo que dio instrucciones a la Emperatriz (ahora el Emperador se hallaba en el Norte de África) para que no siguiera adelante con ese casamiento (8 de mayo 1535).

El segundo de los pleitos en que se vio envuelto el Almirante es posterior, de agosto de 1536, y se lo puso su cuñada, doña Ana de Moncada, madre de doña Ana II de Cabrera, entre otras cosas, porque don Fadrique la había agraviado con palabras injuriantes y había ordenado, como señor del condado, que no viviese con su hija. El Almirante se defendió diciendo que si la había echado de casa de su sobrina era porque doña Ana de Moncada creía que su hija se había malcasado con don Luis Enríquez, también sobrino de don Fadrique, y que por tanto consideraba lógico que estuviese alejada de su yerno. Por lo que respecta al agravio negaba haber dicho ninguna palabra de injuria. Nunca se concluyó nada al respecto.

Si Boscán alude a algún pleito, por fuerza ha de ser al primero, y no sólo por cuestión de fechas, sino también porque en él hubo jueces y una sentencia a favor de una de las partes, aunque no sabemos si la sentencia se dio a conocer en ausencia o presencia del Almirante, quien en esa época, con casi setenta y cinco años cumplidos, ya vivía retirado en su ciudad natal, Medina de Ríoseco, y sólo en ocasiones muy excepcionales visitaba la corte. Al final de sus coplas, al dudar de si su oponente era o no era un personaje poderoso, el poeta de Barcelona podría estar refiriéndose a su papel en ese pleito, que no fue tan decisivo como para lograr una sentencia favorable, y quizá también, cuando lo llama irónicamente santo, por esa imagen que da siempre de sí mismo de amante de una sola mujer, pueda hacerse eco del apodo (el santo) que se acabó aplicando al conde de Ureña a raíz de sus dos desposorios ${ }^{12}$.

Si Boscán, como parece, al escribir uno de los muchos poemas dirigidos al Almirante, tiene presente el pleito que su interlocutor mantuvo con el conde de Ureña, y en concreto la sentencia dictada en marzo de 1535, por fuerza esos poemas en que habla de su abandono de la corte hubo de redactarlos en torno a esa fecha. No muy posterior debe de ser el poema compuesto «en respuesta a una en que le preguntaban si después de venida la corte era mayor su mal y si la gente le congojaba». Ese poema Boscán parece escribirlo en Barcelona con motivo de la presencia en ella de la corte, y en vida de nuestro poeta la corte estuvo en la ciudad condal en diversas ocasiones, pero sobre todo entre el 30 de abril y el 27 de julio de 1529 y entre el 3 de abril y el 30 de mayo de 1535 , cuando Carlos I reunió su poderosa armada rumbo a Italia, la primera para ser coronado como Emperador en Bolonia, y la segunda con destino a las costas africanas, para la conquista de La Goleta y Túnez. En 1529 Boscán pudo viajar

\footnotetext{
12 Véase J. B. de Avalle-Arce, Cancionero..., pág. 159.
} 
a Italia en el séquito imperial, pero también pudo incorporarse a él unos años más tarde, y en 1535 es seguro que se quedó en su ciudad, cuando ya había decidido cambiar de vida.

Boscán debe referirse, pues, a la llegada de la corte a su ciudad la segunda vez, la de abril-mayo de 1535, porque, como hace en los poemas que intercambia con el Almirante, establece una relación muy directa entre la corte y los sentimientos amorosos experimentados en un pasado no demasiado lejano. $\mathrm{Si}$, por ejemplo, abandona la corte a finales de 1534 o principios de 1535 , y con ella unos amores de los que se arrepiente cuando regresa a Barcelona, el paso de la corte en abril y mayo de 1535 por su ciudad podía abrir viejas heridas. Por historiadores como fray Prudencio de Sandoval, sabemos que en Barcelona se habían congregado doce mil españoles, ocho mil alemanes, otros tantos italianos y dos mil portugueses, y que «era tanta la gente noble y común, que no se podía andar por las calles» (492 b). Quizá, por esa avalancha humana, pueda entenderse una de las preguntas que se recoge en el epígrafe: «si la gente le congojaba» ${ }^{13}$.

No muchos meses antes Boscán debió de pergeñar otro poema enderezado al Almirante de Castilla en que responde a una pregunta de su interlocutor sobre «si el mal que tenía lo había traído de Castilla o si lo había habido allí», y nuestro poeta le aclara que le había sobrevenido en el lugar donde se halla en ese momento, porque emplea el adverbio deíctico «aquí». Desde luego Boscán podía estar contestando desde cualquier parte de la geografía peninsular (más difícil es que lo hiciera desde fuera de ese ámbito), pero, por su vinculación con los otros poemas, debemos pensar que estaba en Barcelona y que fue en su ciudad donde volvió a enamorarse, porque advierte que aún «el golpe está caliente» y que apenas se ha dado cuenta de la herida que ha producido. Confiesa, además, que la causante de ese nuevo mal «no es ausente», y que el dolor que debe soportar todavía no se ha hecho crónico, porque lo siente con tanta intensidad, que por fuerza ha de ser muy reciente: como mucho «no pasa del seteno» desde el día en que empezó a notarlo.

\section{AFINIDADES ENTRE LOS LIBROS I, II Y III}

Si volvemos al primer poema que Boscán dirige al Almirante de Castilla y en que habla de un cambio de lugar y sentimientos entenderemos ahora mucho mejor el sentido de semejantes transformaciones. Al dejar la corte deja todo un mundo de pasiones de las que termina arrepintiéndose para empezar una nueva

\footnotetext{
13 En los meses de junio y julio de 1529 también se produjo en Barcelona una gran aglomeración de gente, que la ciudad notó por una importante subida de los precios, según recuerda $\mathrm{M}$. Fernández Álvarez, Carlos V, el césar y el hombre, Madrid, Espasa-Calpe, 1999, pág. 410, n. 44.
} 
vida que quizá aún no le satisface del todo, al lado de una mujer que seguramente con los años se convertirá en su esposa. En ese poema el barcelonés introduce algunas ideas que después acabará desarrollando en sonetos que decidirá colocar en la parte final del libro II de la edición de sus obras. Si leemos con atención la segunda de las estrofas del poema en cuestión nos percataremos de afinidades muy claras y obvias con uno de los sonetos que mucho después escribe pensando en esa parte final de su libro II, el que comienza «Amor m'envía un dulce sentimiento», y en el que anuncia la buena noticia de que por fin ha llegado al puerto después de haber hecho frente, en la alta mar de las pasiones, a innumerables tormentas de amor. No dice Boscán que haya dejado de amar, sino que es objeto de un nuevo sentimiento, muy distinto a los que haya podido experimentar en el pasado, y que ese nuevo sentimiento, que califica de «dulce», es obra de Amor, que lo ha cambiado radicalmente, produciendo en él una serie de transformaciones milagrosas, la resurrección en un nuevo amante, con cuerpo y alma, porque no es el típico amante neoplatónico:

Hace desto fianza el pensamiento, Mostrando, en mi pasado desconcierto, Que Amor me levantó de frío y muerto, Haciéndome quedar vivo y contento.

El milagro fue hecho' strañamente, Porque resucitando el mortal velo,

Resucitó también la inmortal alma (vv. 5-11)

En el poema con que decide cerrar el libro primero de sus obras distingue entre «los pasados amores» (v. 11) y los «accidentes» «nuevos y mejores» del presente para ilustrar una transformación semejante por obra del propio amor y en el que también interviene el pensamiento:

\author{
Descubro aquellos milagros \\ Que amor me tuvo guardados. \\ Mis pensamientos cansados \\ Se han tornado dulces d'agros, \\ De muertos, resucitados (vv. 16-20)
}

En los dos casos se utiliza el mismo tipo de lenguaje para narrar un milagro tampoco demasiado común entre los poetas cortesanos. El milagro de un nuevo amor que permite a quien lo concibe experimentar sentimientos muy diferentes, y totalmente opuestos, a los que había experimentado en el pasado. Ese nuevo amor Boscán lo identifica, en la Epístola a Diego Hurtado de Mendoza, con el conyugal que le inspira la que ya en ese momento es su esposa, doña Ana Girón de Rebolledo:

Y así yo, por seguir aquesta vía, Heme casado con una mujer 
Que's principio y fin del alma mía.

Ésta m'ha dado luego un nuevo ser,

Con tal felicidad, que me sostiene

Llena de voluntad y el entender.

Ésta me hace ver que'lla conviene

A mí y las otras no me convenían;

A ésta yo tengo y ella me tiene.

En mí las otras iban y venían,

$\mathrm{Y}$ a poder de mudanzas a montones

De mi puro dolor se mantenían (vv. 127-138)

Por eso no hay duda de que en el libro II, a partir del soneto CX, y en el libro III, en los versos de la Epístola que acabamos de citar, el barcelonés elogia el amor conyugal y lo califica de sano, de acuerdo con una tradición que en la literatura española ya se documenta en el Tratado de amor atribuido a Juan de Mena («Amor sano e lícito e honesto es aquel que viene por intervenimiento de matrimonio conyugal» $\left.{ }^{14}\right)$. En el libro I, en cambio, no parece aún introducir una alabanza de ese estilo, porque los poemas que lo configuran, salvo el primero, los escribió antes de principios de 1538, cuando todavía no se había casado con la dama valenciana.

Sin embargo, en el primer poema dirigido al Almirante de Castilla, el que elige para clausurar ese libro I, podía estar refiriéndose al amor que en esa época empezaba a inspirarle la que en el futuro acabaría convirtiéndose en su esposa. Si abandonó la corte a finales de 1534 o principios de 1535, al llegar a Barcelona se reencontraría con doña Ana, a quien debería conocer desde antes del 5 de julio de 1533, que es la fecha del documento en que don Fernando, el tercer duque de Alba, le hace entrega de 2500 ducados «para ayuda de su casamiento» ${ }^{15}$. Aunque el texto no aclara a qué casamiento se refiere, parece más que probable que ha de ser el que en esa fecha ya tiene proyectado con doña Ana, y que se acabó demorando más de seis años, por razones que desconocemos. Si en esa fecha ya piensa en casarse con ella, debió conocerla bastante antes, pero en los años inmediatamente anteriores nuestro poeta no se hallaba en Barcelona, ni tan siquiera en la península, como comprobaremos enseguida.

Ya ha quedado claro que Boscán estaba en Ratisbona después del 28 de febrero de 1532, porque Garcilaso lo menciona a propósito de una boda celebrada en una ciudad alemana, seguramente en julio de ese año. En los meses siguientes el barcelonés participó en la campaña de defensa de Viena, y después siguió al Emperador hasta Bolonia, donde, formando parte de su corte, entró a mediados de noviembre de 1532 y de donde salió el 28 de febrero de 1533.

\footnotetext{
14 Reproducido en Tratados de amor en el entorno de "Celestina» (siglos XV-XVI), ed. Pedro M. Cátedra, Madrid, Sociedad Estatal España Nuevo Milenio, 2001, pág. 36.

15 El documento lo aduce Martín de Riquer, Juan Boscán..., pág. 16.
} 
Después pasó por diversas ciudades italianas (Pavía, Milán y Alejandría) hasta llegar a Génova, donde el ocho de abril, un día antes de embarcar hacia Barcelona, recibió un importante nombramiento de Carlos V. El 22 de ese mes ya estaba en la ciudad condal, a la que habría llegado por tierra tras desembarcar en Rosas por culpa del mal tiempo, y en la que posiblemente le estaría esperando doña Ana. La corte del Emperador se quedó en la ciudad condal varios meses, porque en ella también se hallaban la Emperatriz y sus dos hijos Felipe y María; Carlos V dejaba a su familia en Barcelona para inaugurar el 19 de junio las cortes que había convocado en Monzón, de donde hubo de volver urgentemente a la ciudad condal por unas calenturas de la Emperatriz. Ya recuperada doña Isabel regresaba a Monzón el 12 de julio, y estuvo en la villa aragonesa hasta finales de diciembre. Junto a su esposa e hijos pasó el fin de año en Zaragoza y al cabo de quince días se trasladó a diferentes ciudades de Castilla la Vieja (Toledo, Ávila, Valladolid, Palencia, etc) para terminar convocando cortes en Madrid el 20 de octubre de 1534, de donde partió el 2 de marzo del año siguiente para acometer la conquista de Túnez.

Desde la estancia en Alemania en la primavera de 1532 hasta el fin de año de 1533, Boscán debió de estar siempre al lado del Emperador, cuya corte abandonaría en Castilla, bien a finales de 1534 o muy a principios de 1535, para instalarse definitivamente en Barcelona pensando en su boda con doña Ana Girón de Rebolledo. Sin embargo, no sabemos cuándo viajó a Alemania, si en la fase más militar de la campaña, cuando la nobleza castellana y aragonesa decide prestar su apoyo al Emperador para la defensa de Viena, o mucho antes, cuando aún primaba el objetivo religioso, para salvar el cristianismo de un nuevo cisma. Es poco probable que embarcara con el séquito imperial en el puerto de Barcelona el 28 de julio de 1529 para asistir a la coronación de Carlos $\mathrm{V}$ en Bolonia, porque en diciembre de ese año podía estar preparando la boda con doña Isabel Malla, según se deduce de un documento del 15 de diciembre por el que el duque de Alba, don Fadrique, le concede 600 ducados de oro, pagaderos a los quince días de haberse casado ${ }^{16}$. Sin embargo, Boscán nunca llegó a casarse con doña Isabel, y no sabemos por qué.

Quizá por esas fechas conociera a doña Ana, y que, desde un primer momento, la creyera mejor candidata para ser su esposa. Es una conjetura verosímil, pero que no puede probarse. También pudo suceder que tras el viaje a Alemania y Viena Boscán hubiera cambiado de parecer y rompiera su compromiso con doña Isabel: siempre tuvo fama de veleidoso y mudable, y de las dos cosas, como hemos visto, lo acusa el Almirante de Castilla. Ocurriera lo que ocurriera lo cierto es que en julio de 1533, al poco de regresar de la campaña vienesa, decidió contraer nupcias con doña Ana.

\section{Ibíd.}


Del amor por doña Ana creo que Boscán habla en el poema que cierra el libro I, pero todavía no lo hace en los términos en que lo hará cuando ya se haya casado con ella en septiembre de 1539. Sin embargo, en ese poema introduce ya elementos que aparecerán en los sonetos del libro II y en la epístola del libro III, al referirse a su futura esposa como un nuevo amor, «tan honrado mal» (v. 47), por el que se arrepiente de los otros anteriores, que califica de «viejos pecados» (v. 62) y en los que teme volver a caer:

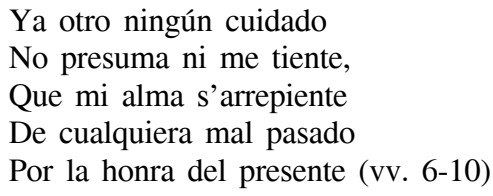

Al oponer los «viejos pecados» con «la honra del presente» Boscán está distinguiendo los dos tipos de amor que confiesa haber sentido en los otros dos libros: un amor situado en el pasado y otro en el presente, que le proporciona «honra», ya en posible alusión al amor de tipo conyugal, y que quiere perpetuar en el futuro. Es verdad que aún no considera ese nuevo amor exento de mal y de sufrimiento, y que lo define con las insufribles paradojas de la poesía de cancionero, tan características de todo el libro I, de los sonetos más tempranos del libro II y del capítulo y epístola amorosa del libro III:

El corazón, que de suyo

No puede padecer llaga,

Agora ya no se paga,

Sino cuando le destruyo

Porque más se satisfaga (vv. 21-25)

Quizá el poeta no experimente los tormentos de antaño (por eso cree que su corazón está a salvo de cualquier herida), pero no puede zafarse de esos tics del pasado, impregnados de un evidente masoquismo, al caer en la tentación de haber de sufrir para estar satisfecho consigo mismo, porque todavía no conoce otra forma mejor de amor que la que ha aprendido de los poetas nacionales.

\section{LA CRONOLOGÍA EN EL LIBRO I}

Para la publicación de sus poemas en octosílabos, Boscán no tiene en cuenta los criterios adoptados por los autores medievales, quienes solían ordenarlos en sus cancioneros individuales o colectivos por géneros y/o temas ${ }^{17}$. En el li-

17 Para esos criterios, usados en determinados cancioneros de autor, como el de Villasandino dentro del Cancionero de Baena, o el de Encina publicado de manera independiente en 1496, 
bro I sólo incluye coplas de arte menor, y nunca usa las de arte mayor, casi todas ellas de carácter amoroso, a excepción de un villancico, de varios autores, de tono satírico. Es posible que para la ordenación de los veintisiete poemas que acaba eligiendo siga un criterio cronológico, de acuerdo con el cual empezaría introduciendo los de la época juvenil para rematarlos con uno inspirado, ya en la madurez, por la que había de ser su esposa.

Si el último poema puede fecharse, como ya hemos visto, a finales de 1534 o principios de 1535, el resto, en cambio, no ofrece datos precisos que permita situarlos en una época determinada. Sólo los villancicos de autores diversos, incluidos ya en la parte final del libro, podrían correr la misma suerte que el poema veintisiete, porque se hacen eco de un incidente ocurrido en palacio y protagonizado por uno de los habituales de la corte, don Luis de la Cueva, que solía ir siempre acompañado por su hermano, don Bartolomé, hijos del duque de Alburquerque. En alguna fiesta cortesana don Luis había bailado con una dama, y lo había hecho de manera que había llamado la atención de todos los asistentes: o bien no era un virtuoso del baile, o bien se había caído o tropezado al ejecutar alguno de los movimientos. Además había elegido como pareja a una dama que, a juzgar por el apodo con que era conocida, no debía gozar de muy buena reputación: «porque bailó en palacio con una dama que llamaban 'La Pájara'».

Garcilaso, como hemos visto, había dedicado una copla a Boscán con una ocasión prácticamente idéntica, mucho más fácil de fechar, porque desde el título precisaba que había tenido lugar en Alemania, y los dos amigos habían coincidido en ese país en el mes de julio de 1532. Los villancicos que publica el barcelonés, y en el que participan nobles de la corte de Carlos V, podían referirse al mismo baile, pero, para admitir tal hipótesis, hay que pensar que el duque de Alba que compone uno de ellos es don Fernando, que había llegado a Ratisbona en compañía de Garcilaso, y no su abuelo don Fadrique de Toledo, que había muerto un año antes. Tampoco está claro si don Luis de la Cueva estuvo o no estuvo en Ratisbona, porque el Emperador, estando en Augsburgo, entre junio y diciembre de 1530 , lo nombró coronel de una compañía de soldados españoles que tenían la misión de detener el avance de los turcos a través de Hungría. No parece que don Luis se reintegrara al ejército imperial antes de la llegada de Carlos V a Viena, ocurrida el 23 de septiembre de 1532, si es que lo hizo entonces ${ }^{18}$. Desde ese día hasta el 4 de octubre, que es cuando el Em-

véase V. Beltrán, «Tipología y génersis de los cancioneros. El Cancionero de Juan del Encina y los cancioneros de autor», en Humanismo y literatura en tiempos de Juan del Encina, ed. Javier Guijarro Ceballos, Salamanca, Ediciones Universidad de Salamanca, 1999, págs. 27-53.

${ }^{18}$ En su Historia fray Prudencio Sandoval ofrece el dato: «Envió el Emperador desde Augusta por coronel de aquellos españoles de Hungría a don Luis de la Cueva.... En el cual cargo estuvo hasta que agora vino el Emperador contra el turco, y se resumieron estas compañías en 
perador abandona la capital austriaca, don Luis sí pudo coincidir con todos los autores que le escriben el villancico satírico, pero es poco probable que en semejante clima prebélico en la corte imperial se celebrara ninguna fiesta, ni tan siquiera para festejar la retirada de Solimán, y tampoco por esas fechas es segura la presencia de Garcilaso entre el séquito de Carlos V.

El baile de don Luis de la Cueva debió de tener lugar en otro momento en que los diferentes nobles que escriben los famosos villancicos coincidieron con él. Ese momento deberíamos remontarlo a las bodas entre el Emperador e Isabel de Portugal, celebradas en Sevilla entre marzo y mayo de 1526, o al período de su luna de miel en Granada entre mayo y diciembre de ese año. Si Boscán estuvo en las dos ciudades ininterrumpidamente hasta diciembre (en la carta dirigida a la duquesa de Soma reconoce haber estado en la segunda), Garcilaso no está probado que se hallara en ellas, y de haberlo estado, lo estaría en dos etapas distintas, una desde el 25 de febrero hasta principios de mayo, y la otra desde mediados de noviembre hasta diciembre. La boda imperial tuvo lugar la noche del sábado del diez de marzo, y en los días posteriores, al recibirse la noticia de la muerte de doña Isabel, hermana del Emperador y reina de Dinamarca, y decretarse por tanto luto oficial, se suspendieron los actos festi$\operatorname{vos}{ }^{19}$. Entre los acompañantes del Emperador a su llegada a Sevilla, fray Prudencio menciona a tres de los autores de los villancicos en cuestión. Por consiguiente el baile de don Luis debe situarse después de la llegada de Carlos V a la ciudad hispalense, o bien entre finales de marzo y principios de mayo, o bien entre mediados de noviembre y principios de diciembre de 1526.

\section{Petrarca, Ausiàs March y JoRge MANRIQue EN El LIBRo I}

Los otros poemas del libro I no se dejan fechar con tanta facilidad, ni tan siquiera los que presentan una clara deuda con Petrarca, a quien Boscán habría podido leer en cualquier momento de su vida, incluso en su adolescencia, cuando hizo su primer viaje a Italia. Pero es curioso que elija para el poema central de ese libro I uno inspirado casi en su totalidad por una canción del poeta florentino, y que el poema en cuestión no introduzca más que una serie de símiles con diferentes elementos de la naturaleza, desde el ave fénix a dos tipos distin-

las demás de su ejército, salvo la del comendador Cerdán y la suya, que quedaron» (444 a). En ese punto de la historia el Emperador ya había abandonado Ratisbona, y podía estar entre Linz y Viena.

19 Lo cierto es que no está demasiado claro cuándo el Emperador recibe la noticia de la muerte de su hermana, si antes de llegar a Sevilla, si cuatro o cinco días después de su llegada o si el 21 de marzo. Tampoco se sabe cuántos se declararon de luto, que debieron ser bastantes, como se desprende del testimonio de fray Prudencio. 
tos de fuentes, sin ofrecer ningún punto de inflexión con respecto a los poemas anteriores.

Por el principio Boscán no decide abrir ese libro con un poema prólogo, sino que opta por incluir un villancico sobre el tema de la mirada como una manera de empezar la narración de sus amores (más a re que a persona). Acto seguido reproduce unas coplas en que ofrece más detalles de su enamoramiento y en que duda de si ya estaba enamorado antes de verla por primera vez. Para toda esa escenificación del amor, nuestro poeta pudo tener en cuenta la primera edición barcelonesa de la obra de March en que aparecía como cuarto poema del volumen el que suele ser el 101 de las ediciones actuales.

En esa edición su preparador, Boscán, Folch de Cardona o quién fuera, demuestra un preciso conocimiento del Canzoniere de Petrarca al querer presentar los poemas del valenciano con el mismo orden que el italiano previó para los suyos, especialmente para el inicio. Elige el actual poema XXXIX como prólogo porque reconoce en su primera estrofa una interpelación a los lectores similar a la que Petrarca introduce en su soneto proemio. Para el segundo lugar escoge el IV seguramente porque lo contempla como una prolongación del primero al reconocer en sus versos un dilema, entre un deseo sexual y otro espiritual, que el poeta resuelve, a favor del segundo, después de un debate entre las partes implicadas, el cuerpo y el entendimiento. Inmediatamente a continuación del IV coloca el LXVI porque comprueba que en su estrofa final March también sitúa el día de su enamoramiento (el tempus) un viernes santo, al igual que el florentino en su soneto 3. Y para rematar este initium narrationis inserta el actual CI al advertir en la segunda estrofa la descripción de la primera visión de la dama (la causa), en sintonía con el soneto II del Canzoniere y un pasaje del Triumphus Cupidinis ${ }^{20}$.

\section{LA IMAGEN DEL RAYO Y EL TRUENO}

Para su libro I Boscán prescinde de las piezas proemiales, y también de situar su enamoramiento en un día preciso, y opta por abordar directamente la causa de su amor, que es la contemplación de la amada, cuyas consecuencias presenta en consonancia con la segunda estrofa del actual poema CI de March. Para el segundo lugar el barcelonés piensa en unas coplas más extensas en que, tras definir la naturaleza de su mal, vuelve a insistir en el conocimiento de la amada para introducir la duda de si se enamoró antes o después de verla. Para semejante cuestión recurre a la imagen del rayo y el trueno, en que el rayo se-

\footnotetext{
${ }^{20}$ Para la cuestión, véase el iluminador trabajo de Ll. Cabré, «Un lugar de Petrarca, de March a Herrera (pasando por la edición de 1543)», en prensa.
} 
rían los ojos de la amada y el trueno el amor que el poeta nota tras ser testigo de su resplandor:

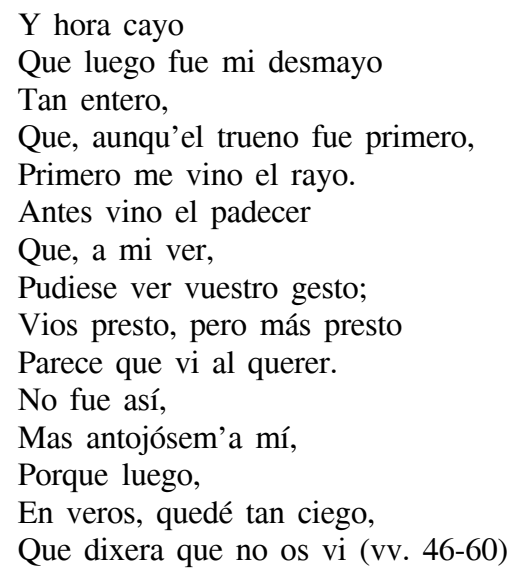

En los versos siguientes sigue desarrollando esa imagen al identificar implícitamente el rayo con la luz (de los ojos y del rostro de la amada) que lo deja ciego y el trueno con el fuego de amor que lo consume y hace sufrir. En la tormenta el rayo se deja ver antes de sentirse el estruendo del trueno, pero el poeta no lo tiene claro al afirmar que a él primero le vino el rayo, como si eso fuera lo anómalo. Boscán pudo inspirarse para esa imagen en la famosa canción del Comendador Escrivá, quien la utiliza para aplicarla no al amor sino a la muerte:
Ven como rayo que hiere,
Que hasta que ha herido
No se siente su ruido
Por mejor herir do quiere ${ }^{21}$.

El poeta barcelonés tampoco se ha percatado de la llegada silenciosa del rayo hasta que no lo ha fulminado, hasta que ha oído el ruido tras el impacto con su corazón, cuando ya no podía hacer nada para evitarlo. Por eso piensa que se ha podido enamorar incluso antes de contemplar a su dama, o también, como explica al final, porque el resplandor de la mirada lo ha cegado de tal forma, que ha creído no haber visto nada y sólo ha percibido el estruendo del trueno cuando ya ha arrasado su corazón.

Los poetas del dolce stil novo usaron la imagen del rayo como variante de la flecha de Cupido, pero muy pocos explotaron de la manera en que lo hace el

21 Excelentemente editada y anotada por Vicenç Beltrán, Poesía Española. Edad Media: lírica y cancioneros, Barcelona, Crítica, 2002, pág. 646. 
nuestro $^{22}$. Guittone d'Arezzo, por ejemplo, en uno de sus sonetos, simplifica el proceso de contemplación equiparándolo con el trueno:

Quando la veggio paremi uno trono,

Un foco ardente che me fiere al viso;

Allora guardo intorno se veruno

Vede la pena mia che m'ha conquiso ${ }^{23}$

Guido Guinizzeli, en otro soneto, describe las consecuencias que tiene para él el saludo de su dama, y lo compara con el relámpago que entra por la ventana de una torre y destroza cuanto halla dentro:

Lo vostro bel saluto e'l gentil sguardo

Che fate quando v'encontro, m'ancide...

Per li occhi passa come fa lo trono,

Che fer' per la finestra de la torre

E ciò che dentro trova spezza e fende ${ }^{24}$;

en otro soneto, refiere el modo en que intentó enfrentarse a Amor y cómo fue abatido por él, «come lo trono che fere lo muro» (5). En una de sus canciones de amor, se dirige a su dama para explicarle «che' $\mathrm{n}$ aire nasce un foco per rincontrar di venti», y que si el fuego en cuestión, que es el relámpago, no se deshace al entrar en contacto con las nubes («se non more 'n venire in nuviloso loco») «arde immantenenti», y que así de sus deseos, al chocar con el aire, se ha originado un fuego similar que sólo puede atemperar con las lágrimas y el dolor $^{25}$. Cino de Pistoia, en otro soneto, identifica las saetas de Cupido, salidas de los ojos de la dama, con el relámpago acompañado de trueno:

Tardi m'accorgo, dacché morto sono,

Ch'Amor degli occhi d'esta donna passa

Come saetta la qual vèn con trono,

Ché tutto'l core altrui dentro fracassa ${ }^{26}$.

Dante, en una de sus canciones, la de la «montanina», cuenta cómo fue herido de amor en medio de los Alpes por una serranilla, y recuerda la herida que

${ }^{22}$ Para el motivo véase especialmente Enrico Fenzi, «Ancora sulla Epistola a Morello e sulla 'montanina' de Dante (Rime, XV)», Tenzone, IV, 2003, págs. 53-55; Vicente Beltrán, ed., Poesía Española... pág. 646; y Estela Pérez Bosch, «Acerca del petrarquismo cuatrocentista: los poetas valencianos del Cancionero general», en Convivio. Estudios sobre porsía de cancionero, eds. Vicenç Beltrán y Juan Paredes, Granada, Universidad de Granada, 2006, pág. 697.

${ }^{23}$ Le rime di Guittone d'Arezzo, ed. Francesco Egidi, Bari, Laterza, 1940, pág. 208.

${ }^{24}$ Poeti del duecento, 2.II. Dolce stil novo, ed. Gianfranco Contini, Milano-Napoli, Ricardo Ricciardi,1995, pág. 468.

${ }^{25}$ Poeti del duicento..., pág. 458. Las explicaciones de Guido sobre el relámpago están tomadas de Brunetto Latini, Tresor, CV, 7.

${ }^{26} \mathrm{El}$ soneto entero puede leerse en http://www.silab.it/cgi-bin/poeweb.exe. 
le había causado como si fuera un trueno que le alcanzó la espalda, «qual fu quel trono che mi giunse a dorso» $(57)^{27}$. A esta canción parece aludir Dante en la carta que escribe al señor Morillo, marqués de Malaspina, en la que explica la aparición de una extraña mujer primero como relámpago descendido del cielo y después como un trueno que lo aterroriza y quema de amor:

Cum primum pedes iuxta Sarni fluenta securus et incautus defigerem, subito heu mulier ceu fulgur descendens apparuit nescio quomodo... O quam in eius apparitione ostupui; sed stupor subsequentis tonitrui terrore cessavit. Nam sicut diurnis coruscationibus illico succedunt tonitrua, sic inspecta flamma pulchritudinis huius amor terribilis et imperiosus me tenuit ${ }^{28}$.

('Cuando primero, estando seguro e incauto, planté los pies junto a la corriente del Arno, de repente, ¡ay de mí! se me apareció no sé muy bien cómo una mujer como un relámpago que desciende del cielo... ¡Oh cuán estupefacto quedé por esta aparición, pero el estupor cesó por el miedo del trueno posterior. Pues como del mismo modo que a los relámpagos brillantes como el día les suceden inmediatamente los truenos, así con la llama contemplada de esta belleza un amor terrible y dominante se apoderó de mí...').

En la canción II del Convivio, en cambio, describe la mirada de la mujerfilosofía de la que se ha enamorado con la fuerza de un trueno que rompe los vicios que envilecen a los hombres, «sua bieltà piote fiammelle di foco..., e rompon come trono l'innati vizi che fanno altrui vile» $(63-67)^{29}$. Sennuccio del Bene, atento a la carta de Dante, narra los efectos que le produjo la irrupción de su dama como si hubiera recibido por sorpresa el impacto de un trueno, «Subitamente come son li troni/ mi mostrò donna di tanta biltate» (5-6) ${ }^{30}$, y su amigo Petrarca, en un soneto en que cree estar preparado para repeler un nuevo ataque de Amor, se confiesa sorprendido por la mirada y el saludo de Laura, que presenta con la imagen del relámpago y el trueno:

Come col balenar tona in un punto,

Così fu'io de' begli occhi lucenti

Et d'un dolce saluto inseme aggiunto (12-14) ${ }^{31}$

Tres sonetos después, en uno de los dedicados precisamente a Sennuccio, escribe desde Provenza para decirle que se siente a salvo de los relámpagos que lo han acompañado durante el viaje pero no del amor que ahora, en la tierra de

27 Dante Alighieri, Vita nuova. Rime, ed. F. Chiappelli, Milano, Mursia, 1965, pág. 165.

${ }^{28}$ La Epístola de Dante está reproducida íntegra en el trabajo de Enrico Fenzi, pág. 47.

29 Dante, Opere minori, ed. Cesare Vasoli y Domenico de Robertis, vol. II, tomo I, MilanoNapoli, Ricardo Ricciardi, 1995, pág. 287.

${ }^{30}$ No he podido leer el soneto completo de Sennuccio, citado tanto por Enrico Fenzi, pág. 54, como M. Santagata, pág. 516.

31 Petrarca, Canzonieri, ed. M. Santagata, Milano, Mindadori, 1996, págs. 514-516. 
Laura, nota que vuelve a revivir en su alma. Por lo que respecta a la tormenta, aclara que el aura de la región ha limpiado el cielo de nubes y ha alejado los truenos («l'aura dolce et pura,/ ch'acqueta l'aere, et mette i tuoni in bando»), en clara referencia a una de las propiedades del laurel, la de su inmunidad a los rayos, y de Laura, la de su invulnerabilidad a las flechas de Cupido y al amor.

De todos los textos aducidos Boscán muestra una mayor afinidad con la epístola de Dante, al distinguir dos fases, la de la contemplación de la amada, equivalente al relámpago, y a sus efectos inmediatos, similares a los del trueno. Además, de manera implícita, podía estar sugiriendo que se hallaba tan desprevenido y descuidado como lo estaba Dante a orillas del Arno, para así recrear la situación que Petrarca presenta al principio de su Canzoniere, concretamente en su soneto II, y que ya antes habían reproducido Bernard de Ventadorn y Peire Vidal, y después Ausiàs March ${ }^{32}$.

El barcelonés también podía haberse inspirado en textos clásicos en que se usaba la misma imagen. En la Eneida, de Virgilio, Venus reconquista el amor de Vulcano con la intención de pedirle nuevas armas para su hijo Eneas; así lo abraza con tal suavidad, que enciende en el marido una llama semejante a la del relámpago que corta el cielo:

Ille repente

Accepit solitam flammam notusque medullas

Intravit calor el labefacta per ossa cucurrit:

Non secus atque olim tronitru cum rupta corusco

Ignea rima micans percurrit lumine nimbos (VIII, 388-394)

('Él [Vulcano] en un instante recibió la acostumbrada llama, y un calor conocido entró por sus medulas y recorrió los huesos debilitados. Así como cuando a veces el surco encendido que salta del trueno resplandeciente recorre con su luz rota las nubes').

En sus comentarios Servio entiende que «el surco encendido» es el relámpago y que la imagen ilustra la velocidad del amor que en un momento golpeó a Vulcano: «alii rima micans fulgetram dicunt; et hoc ad velocitatem amoris qui momento Vulcanum percussit» ${ }^{33}$. Esta escena de amor entre los dos dioses ofrece una variante de la imagen tal y como la usaron los poetas italianos, y es que la diosa enamora a su esposo no con la mirada, ni con el saludo, sino con un abrazo voluptuoso.

\footnotetext{
32 Paras las referencias de los poetas provenzales, véase Enrico Fenzi, pág. 53.

${ }^{33}$ La cita de Servio, junto al pasaje de Virgilio, está aducida por Enrico Fenzi, pág. 55.
} 


\section{El POSIBLE CANCIONERO DE MANRIQUE}

Para las dudas que tiene el poeta sobre cuándo se ha enamorado, si antes o después de la visio, nuestro poeta pudo tener en cuenta unas coplas de Jorge Manrique, las que en el Cancionero general de 1511 abren la colección de obras del poeta castellano, al menos de tema amoroso. El volumen de Hernando del Castillo es el testimonio que ha conservado casi la totalidad de la poesía de Manrique, y es por ese motivo que la crítica ha supuesto que el compilador valenciano pudo haber manejado un cancionero completo del autor. A pesar de repartir sus poemas en las diferentes secciones del volumen, Castillo incluyó un buen número de ellos en su segundo apartado, el dedicado a «Obras de amores», que debió de reproducir en el orden en que debía estar en su modelo ${ }^{34}$.

Es por tanto posible que el poema inicial de ese apartado de tema amoroso ya lo fuera en el cancionero personal de Manrique, y que de ese modo su autor lo situara en ese lugar pensando en una estructura petrarquista ${ }^{35}$. Quizá por eso Manrique decide introducir una variante en ese initium narrationis al presentar su enamoramiento como anterior a la visio, porque el poeta confiesa haberse enamorado de oídas, al haber recibido primero mensajes de otros amantes que alababan a la dama en cuestión. Llevado por tales alabanzas el poeta decide ir a verla en persona, y se plantea ese conocimiento visual como si fuera la conquista de una fortaleza, en cuya empresa queda atrapado, sin poder salir, porque se ha rendido por completo a su dueño.

Al margen de esas dudas sobre la visio, Boscán contrae otras deudas con ese y otros poemas de Manrique. El poeta barcelonés, después de no saber si primero ha visto el relámpago o ha recibido su impacto en forma de trueno, describe a la amada con atributos casi divinos, al considerarlo ininteligible para su entendimiento:

Mas el seso con que entiendo,

No pudiendo

Entenderos, no sé ver

Cómo pudo yo querer

Aquello que no comprendo.

No me falta

Buen remedio en esta falta,

34 Véase en ese sentido el estupendo trabajo de V. Beltrán, «Tipología y génesis de los cancioneros: el caso de Jorge Manrique», en Historias y ficciones: coloquio sobre la literatura del siglo XV, eds. R. Beltrán, J. L. Canet y J. L. Sirera, Valencia, Universidad de Valencia, 1992, págs. 167-183, y especialmente pág. 170.

35 Véase B. Morros, «Manrique y Petrarca. Estudios del petrarquismo en la literatura del siglo XV», Medioevo Romanzo, XXIX, 2005, pág. 135. 


\section{Porqu'en veros,}

Por eso de no entenderos,

Entiendo que sois muy alta (vv. 61-70)

En la última estrofa explica que no ha podido comprender a la amada porque ha sido incapaz de hacer intervenir para ello el alma racional, al sentirse vencido o superado por el apetito o voluntad y todavía demasiado inclinado a los sentidos del alma sensitiva. Precisamente esos sentidos, plenamente corporales y gobernados por la voluntad, no por la razón, acaban obteniendo una imagen y opinión de la amada que la convierten en la mujer más bella y apetecible de todas las mujeres que han conocido, y garantizan por ese motivo la fidelidad y la lealtad del amante. Esa seguramente es la verdad de la que se cree poseedor el pensamiento del poeta:

Lo que sois se me declara

Cuando para

Mi seso y a vos no llega;

Porque la luz que me ciega

Luego digo que's muy clara.

Por do siento

Que's ya de mi pensamiento

Mi verdad,

Sobrarme la voluntad

Do falta el entendimiento (vv. 71-80)

En el poema inicial Manrique también reconoce que, aún sin haber visto a su dama, ha perdido su libertad, pero la ha perdido tanto su razón o entendimiento como su voluntad, y no parece que se haya entablado ningún tipo de lucha entre esas dos partes de su alma:

Mas es tal vuestra beldad, Vuestras gracias y valer,

Que razón y voluntad

Os dieron su libertad

Sin poder defenderse ${ }^{36}$

En el Castillo de amor, poema que aparece entre los poemas de tema amoroso incluidos en el Cancionero General, Manrique se identifica como una fortaleza ocupada por su dama e inexpugnable a los ataques del olvido y a las asechanzas amorosas de otra mujer. Para ratificarse en ese propósito dice que su pensamiento no hace más que reproducir la imagen de su amada al considerarla superior a la de cualquier otra dama. Precisamente sitúa su pensamiento en la

\footnotetext{
36 Jorge Manrique, Poesía, ed. B. Morros, Barcelona, Vicens Vives, pág. 4.
} 
torre más alta del castillo, a la que llama verdad, porque quiere garantizarle que no la va a reemplazar por la imagen de otra mujer:

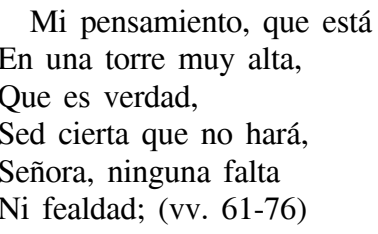

Ahora entendemos mejor la incapacidad de Boscán para poder convertir en idea la imagen de su dama y poder así percibirla con el entendimiento. Para llegar a esa idea de belleza debía contemplar la de la amada en conjunción con la de otras damas, pero ha rechazado de su pensamiento todas esas bellezas para obsesionarse con una que ha considerado superior. De ese modo nuestro poeta ha querido definir el tipo de amor, nada platónico, que va estar presente en la mayoría de textos seleccionados para ese libro I, al igual que había hecho Petrarca en el soneto VI de su Canzoniere, en que se presenta a sí mismo dejándose llevar por el loco deseo, incapaz de controlarlo.

\section{EL NOMBRE DE ISABEL}

En las coplas que ocupan el tercer lugar Boscán decide desvelar el nombre de la dama a quien parece dedicar si no todo al menos una parte importante del libro I: «Señora doña Isabel,/ tan cruel...». No da más pistas sobre la identidad de esa dama, y las conjeturas al respecto no pueden tomarse demasiado en serio. Si creemos a los comentaristas de Garcilaso, entre ellos el Brocense, que identifican a Nemoroso con Boscán, podríamos creer que esas coplas el barcelonés se las dedicó a Isabel Freyre y que hubo de componerlas después de la primavera de 1526, que es cuando la dama portuguesa llegó a España acompañando a la futura Emperatriz. Si, en lugar de hacer caso al Brocense, repasamos las damas con las que Boscán tuvo una relación especial hallaremos a otra Isabel en su vida, a doña Isabel Malla, con quien el poeta habría pensado casarse pero con quien no llegó a hacerlo por razones que seguramente nunca sabremos. El matrimonio con doña Isabel lo debió proyectar el barcelonés en diciembre de 1529 , que es la fecha del documento por el que el segundo duque de Alba, don Fadrique Álvarez de Toledo, le concede 600 ducados para ese enlace.

\section{LAS CRISIS DE AMOR}

En las coplas que ocupan el quinto lugar Boscán reproduce su primera crisis amorosa al decidir dejar de amar a la señora que le ha inspirado los prime- 
ros poemas. Las titula significativamente «Otras desaviniéndose» (hoy podríamos decir «Otras desenamorándose»), y explica en sus versos las razones por las cuales ha tomado esa decisión. Inmediatamente incluye otras en que se arrepiente por haber dado ese paso y en las que no pide más venganza sino contra sí mismo.

Un poco más adelante, después de unas coplas y dos canciones, parece referirse a otra crisis, seguramente provocada por una mujer distinta, no la Isabel del principio. En esas nuevas coplas, a las que pone el epígrafe «Otras determinando de dejar unos amores», se presenta fuera de la prisión de Amor pero arrastrando todavía sus cadenas, y para liberarse de ellas se impone una doble terapia, la ausencia («guardar la vista») y la ocupación del pensamiento en otras cosas que no sean las relativas a la amada («y ocupar el pensamiento»).

\section{UN SONETO Y UNA CANCIÓN DE PETRARCA, CONTAMINADA POR LA «HISTORIA NATURAL» DE PLINIO}

Dos composiciones más adelante, al desarrollar el tópico del alma que anima ubi amat, confiesa que se siente libre porque la suya ha escogido una morada, el corazón de su dama, ya no sabemos de cuál, lo suficientemente ancha y espaciosa como para tener semejante impresión. Al final podría parecer que es correspondido por la amada al admitir que es «en uno dos» y que «hay un ser solo entre nos», pero sólo lo parece porque antes ha explicado que, a pesar de vivir en alma ajena, su dueña no se ha percatado de la presencia del nuevo huésped. Para esa composición no deja de plantear situaciones totalmente contradictorias, como la de ser libre en la prisión o la de pensar que forma una unidad con alguien que no te ama, y para la primera contradicción se ha inspirado en un soneto, el 134, en que Petrarca expresa ésa y otras dentro del género trovadoresco de la devinalh. Si el barcelonés considera el corazón de la amada «ancha prisión» (v. 9), de la que puede salir y en la que puede entrar libremente («no me cerráis ni m’abrís», v. 15), el italiano se presenta en la prisión de Amor con las puertas de entrada y salida también abiertas, ni retenido a la fuerza pero tampoco con el lazo suelto, ni vivo ni muerto:

Tal m'à in pregion, che non m'apre né serra, Né per suo mi riten né scioglie il laccio; Et non m'ancide Amor, et no mi sferra, Né mi vuol vivo, né mi trae d'impaccio (vv. 5-8)

Si nuestro poeta alude a una «afrenta» (v. 17) que su alma debe padecer no es tanto porque tenga esa libertad de entrada y salida de la prisión, sino especialmente porque es víctima de las otras contradicciones de Amor sólo puestas de manifiesto por el cantor de Laura. 
En las coplas reproducidas inmediatamente después de las que acabamos de analizar Boscán rehace más decididamente una canción que Petrarca sitúa a continuación del soneto del que se ha apropiado un verso ${ }^{37}$. Para las coplas en cuestión nuestra poeta, siguiendo su modelo, introduce una serie de similitudes o comparaciones con fuentes y animales míticos para subrayar sus propias contradicciones. De Petrarca toma los dos de los tres animales (el ave fénix y el catoblepas) y las dos fuentes (el italiano habla de una tercera de la que el catalán decide prescindir). Pero el símil con el águila también pudo adaptarlo de Petrarca, concretamente del soneto XIX, en que el poeta italiano distingue tres tipos de animales para equiparse implícitamente con los tres. Si menciona primero a las águilas es para reconocer que, a diferencia de ellas, no puede contemplar el sol de su amada sin recibir daño alguno, y que acabará quemándose como le ocurre a la mariposa, atraída por la claridad del fuego:

Son animali al mondo de sì altera

Vista che'ncontra '1 sol pur si difunde...

Ch'i' non son forte ad aspectar la luce

Di questa donna...

Però con gli occhi lagrimosi e 'nfermi

Mio destino a vederla mi conduce;

Et son ben ch'i' vo dietro a quel che m'arde (1-2, 9-10 y 12-14)

Nuestro poeta, por su parte, concreta más esa propiedad del águila, al hablar de las madres que expulsan de los nidos a las crías que no resisten la mirada fija del sol:

Pues del águila es lo bueno

Que, al que de sus hijos vido

Que no mira al sol de lleno,

Como a hijo que's ageno

Luego l'echa de su nido (vv. 51-55)

Para tal propiedad sin duda se ha inspirado en la Farsalia de Lucano, quien la recuerda al mencionar la prueba a la que los psilos de la Marmárica (un pueblo africano) sometían a los vástagos dudosos de ser hijos de extranjeros (los hacían morder por una serpiente venenosa, al ser los naturales inmunes a cualquier veneno):

Utque Iovis volucer, calido cum protulit ovo

Implumes natos, solis convertit ad ortus:

${ }^{37}$ La influencia de esa canción de Petrarca en las coplas de Boscán ya había sido advertida y estudiada por Margherita Morreale, Castiglione y Boscán: el ideal cortesano en el Renacimiento español, vol. I, Madrid, Anejos del Boletín de la Real Academia Española, 1959, págs. 250-252. 
Qui potuere pati radios et lumine recto

Sustinuere diem, caeli servantur in usus,

Qui Phoebo cessere, iacent... (IX, 902-906)

('Como el ave de Júpiter, cuando ha sacado del huevo caliente a sus hijos sin pluma, los dirige hacia la salida del sol: los que pueden soportar sus rayos y sostener [con la mirada] su luz directa durante el día, son reservados para el servicio de los dioses; los que no resisten a Febo, son echados').

En fechas cercanas a las de Lucano Plinio el viejo, en su Historia natural $(\mathrm{X}, 3,10)$, se refiere a un determinado tipo de águilas, el haliaeto, al que atribuye para con sus crías el mismo comportamiento que el autor de la Pharsalia, tratando de ilegítimo al hijo que no supera la prueba:

Haliaetus tantum implumes etiammum pullos suos percutiens subinde cogit adversos intueri solis radios et, si coniventem humectantemque animadvertit, praecipat e nido velut adulterinum atque degenerem; illum cuius acies firma contra stetit educat ${ }^{38}$.

('Sólo el Halieto obliga, golpeándolos, a sus polluelos todavía sin plumas a contemplar los opuestos rayos del sol y, si lo ve cerrar los ojos o llorar, lo echa del nido como adulterino y vil; cría al que se mantuvo firme [mirando] hacia los rayos').

Plinio parece interpretar el texto de Lucano, al sugerir pero no afirmar claramente que la prueba que el águila somete a sus crías es una prueba de paternidad. Lucano no lo dice en ningún momento, pero la compara con otra, la que un pueblo africano hace pasar a sus hijos, que sí es de paternidad. Siguiendo seguramente a Plinio, aunque también era lector de Lucano, san Isidoro, en sus Etimologías (XII, 7, 10), la recuerda como una prueba para determinar el origen noble de la cría:

Nam et contra radium solis fertur obtutum non flectere; unde et pullos suos ungue suspensos radiis solis obicit, et quos viderit inmobilem tenere aciem, ut dignos genere conservat; si quos vero inflectere obtutum, quasi degeneres abicit $^{39}$.

('Se dice que también que mira directamente los rayos del sol sin volverse; y que por eso pone a sus polluelos dejándolos colgados de sus uñas frente a los rayos del sol, y a los que ve tener la mirada inmóvil los considera dignos de su especie; pero si los ve apartar la mirada los expulsa como viles').

Para el último símil Boscán se ha inspirado en el que Petrarca propone con el fénix, al hallar semejanzas muy evidentes entre ambas aves, también sugeridas

\footnotetext{
38 Uso la edición de H. Rackham, London, Loeb, 1983, vol. III, pág. 298.

${ }^{39}$ Manejo la edición de José Oroz Reta y Manuel A. Marcos Casquero, Madrid, Biblioteca de Autores Cristianos, 1983, vol. II, pág. 106.
} 
por algunas de sus fuentes, como la Historia natural de Plinio, en que el barcelonés podía leer que la legendaria ave tenía el mismo tamaño que el águila («Aquilae narratur magnitudine», X, 2, 3), o que las dos eran de género incierto («suum genus non habent»; X, 3, 11). Si Petrarca había usado una de las propiedades del fénix, la de dirigirse al sol en el momento de morir, para identificarla con sus pensamientos de amor, Boscán ofrecía la misma aplicación pero buscando otra ave con una propiedad similar, y para esa parte recurrió a uno de los tres autores latinos que acabamos de citar. De los tres seguramente se basa en Plinio, a quien parece traducir literalmente, cuando afirma, del pensamiento que no ha superado la prueba, «échole como a bastardo/ de bajo conocimiento» (59-60), «praecipat e nido velut adulterinum atque degenerem» (también podríamos pensar que sigue a san Isidoro, que se expresa en los mismos términos, «quasi degeneres abicit»). Por ese motivo, al aplicar ese símil, explica que el pensamiento que no se ocupa de la amada, que no recrea su imagen resplandeciente, termina por creerlo no suyo sino de otra persona, renunciando a él como si fuera un hijo bastardo, creado por un sujeto humilde. De hecho, el sustantivo latino degener podría traducirse como 'bastardo', y así, por ejemplo, lo hace Alonso de Fuentes en su Suma de filosofía natural (1547), cuando, al hablar de la virtud de los progenitores, recuerda esa propiedad del águila, teniendo presente el pasaje de Plinio:

De lo cual nos dan maravilloso ejemplo muchos animales irracionales y entre ellos lo verá claramente quien la propiedad del águila considerare. La cual, movida por sólo instinto natural, en siendo sus pollos de alguna edad les hace mirar al Sol porque en esto tiene el águila una virtud maravillosa que puede sin turbación alguna mirar al Sol sin que su resplandor turbe ni enflaquezca su vista. Y al hijo que siente que no lo mira con aquella atención e fuerza que ella misma, como a bastardo e incapaz de su hijo, lo expele y echa de su nido para que muera y no que viviendo deje de seguir la propiedad e virtud de sus padres ${ }^{40}$.

No sé si Boscán pudo haber visto una pintura que Pedro Berruguete dedicó a la condesa de Módica, la esposa del Almirante de Castilla, don Fadrique Enríquez, y en la que al artista dibujó un águila sobre la cima de una montaña mirando fijamente el sol y expulsando de su nido a los hijos que no la imitaban. La pintura se la enseñó el propio Almirante a quien la recuerda con tanto detalle, Gonzalo Fernández de Oviedo, en sus Batallas y quincuagenas:

Tornando a nuestro propósito, el señor Almirante don Fadrique 2, de quien principalmente aquí se trata, acuérdome haber visto un retracto al natural de la muy jllustre Condesa su mujer, en una tabla de pincel, e al un lado de dicha imagen estaba una montaña, en la cumbre de la cual avía una águila real

\footnotetext{
${ }^{40}$ Cito por la edición de G. Hérrez Cubino, CILUS, 2000, fol. XXVI r.
} 
puesta en el nido mirando a los rayos del sol ella e sus pequeños hijos [...] E derribados algunos dellos del nido, que caían para abajo a tierra, desechados de la madre, por no ser dignos de que ella los criase, seyendo flacos de vista, e que no avían podido sofrir la claridad del sol, mirándole como incapaces de tal excelençia. E los que quedaban estaban con ella atentos mirando en el [una palabra ilegible] como he dicho. E todo esto muy al natural, con los [una palabra ilegible] que se escribe de la excelente vista del águila, paréceme que ésta era una de las más perfetas pinturas que pintada fue de aquel famoso Berruguete en toda su vida.....La cual el mismo señor Almirante me enseñó en Barcelona, año de 1519, e me dijo que aquella montaña e águila quería de aý adelante traer por timbre de sus armas... ${ }^{41}$

Si Boscán conocía la pintura, o la insignia del escudo de armas del Almirante, podía en ese poema central introducir un recuerdo a la condesa, y lo puedo hacer después de su muerte, ocurrida en 1530. En la pintura, el águila, como explica el autor de las Batallas, representa a doña Ana, de quien don Fadrique quiso ponderar su vista.

En las coplas siguientes Boscán no abandona a Petrarca, sino que lo adopta para empezar una composición y terminar otra. Para esas dos composiciones ha tenido en cuenta un soneto, el CXL, muy próximo al soneto y la canción que ha imitado en las dos series de coplas anteriores, en que el aretino explica cómo Amor se ha erigido en el señor absoluto de su corazón hasta la muerte. Para el primero de los dos poemas, el barcelonés no sólo expresa la misma idea sino que también calca los primeros versos del soneto en cuestión:

Amor, che nel pensier mio vive et regna E'l suo seggio maggior nel mio cor tene...
Amor, que' $\mathrm{n}$ mi pensamiento Rige, manda, suelta y prende, Con tal fuego en ní s'enciende, Que mi ciego entendimiento $\mathrm{Su}$ mismo dolor no entiende

Sin embargo, ofrece una versión un tanto diferente de la conquista de su corazón por parte de Amor. Dice que lo ha engañado, haciéndole creer que en él iba a introducir tanto alegría como tristeza, pero que no ha sido así, que la alegría no ha pasado de la puerta, y que el dolor se ha instalado en sus entrañas, de donde ya no ha podido expulsarlo:

Y cuando quise al amor

Echalle, como a traidor

No pude, que cuando entró,

Do por huésped s'acogió

S'alçó luego por señor. (vv. 26-30)

41 Cito por la edición de J. B. Avalle-Arce, Salamanca, Diputación de Salamanca, 1989, pág. 109. 
Petrarca cuenta que Amor primero se instala en el rostro de Laura para luego refugiarse en su corazón, porque el hijo de Venus no ha sabido adaptarse a las exigencias de castidad de la dama, de quien llega a sentir miedo:

Quella ch'amare et sofreír ne; nsegna

E vol che'l gran disio, l'accesa spene,

Ragion, vergogna et reverenda affrene,

Di nostro ardir fra se stessa si sdegna.

Onde Amor paventoso fugge al core,

Lasciando ogni sua impresa, et piange, et trema,

Ivi s'asconde, et non appar più fore.

Che poss'io far, temendo il mio signore,

Se non star seco infin a l'ora extrema?

Ché bel fin fa chi ven amando more (vv. 5-14)

Los dos poetas identifican el amor que sienten con un apetito totalmente carnal que se erige en señor de sus corazones y que por diversas razones no consiguen expulsarlo de ellos. Los dos poetas temen a amor, pero mientras uno lo teme porque lo ha tiranizado y ha anulado su entendimiento, por un exceso de concupiscencia, el otro, en cambio, se contagia del miedo que amor tiene a Laura precisamente por no haber aprendido a controlar su lascivia y por haber intentado despertarla en la dama que ha elegido como arma más efectiva contra los mortales.

Para la «destreza» con que Amor se adueña del corazón del amante, Boscán podía haber tenido en cuenta el soneto LXXXIX, del Canzoniere, en que Petrarca narra la tentativa de liberarse del yugo amoroso, frustrada por Cupido, al aparecérsele en el camino de huida con un aspecto que le engañó a él y habría engañado a otro mucho más sabio:

Fuggendo la pregione ove Amore m'ebbe Molt'anni a fat di me quel ch'a lui parve...

Diceami il cor che per sé in saprebbe Vivier un giorno; et poi tra via m'apparve

Quel traditore in sì mentite larve

Che più saggui di me inganato avrebbe (1-2 y 5-8)

En las coplas siguientes, las que ocupan el lugar quinceavo, Boscán sigue mostrándose enamorado y se complace en convertirse en el centro de otras muchas paradojas del amor. Espera que su dama ponga fin a todas sus crueldades asestándole el último golpe, el definitivo, el que le provoque la muerte, para concebirlo, no como el último mal que recibe de ella, sino como «la merced primera» (v. 10). Dentro de esas contradicciones recupera algunas de las que había puesto de manifiesto en el poema anterior en que declara sentirse libre en el corazón ancho y generoso de la amada. Ahora reprocha a Amor que ni lo 
retenga ni lo suelte, como había hecho Petrarca en el soneto 134 («Né per suo mi riten né scioglie il laccio», 6):
Y siempre cuanto le pido
Determina negarme,
No quiere escuchar partido,
$\mathrm{Ni}$ menos quiere dejarme
$\mathrm{Ni}$ tomarme por vencido (vv. 61-65)

Boscán se queja de que su amor no tenga más recompensa que el sufrimiento, pero, en cambio, se siente mucho más feliz cuando mayor es el mal que recibe, porque sabe quién se lo provoca; y al final, con esa alegría, puede hacer frente al desdén y la indiferencia de la amada. Por eso remata las coplas afirmando que se entrega a amor porque no pretende abandonarlo hasta la muerte, y para reproducir semejante idea vuelve a traducir literalmente a Petrarca, en concreto el último verso del soneto 134 («Ché bel fin fa chi ben amando more»):

\section{Mi holganza}

Es poner mi confianza

En cuanto el amor quisiere,

Que'l que bien amando muere

Muy honrado fin alcanza (vv. 116-120)

El poeta de Laura había llegado a la misma conclusión pero por razones distintas. En su caso tampoco puede expulsar a Amor de su corazón porque, al notarlo medroso, se apiada de él, y se resigna a acompañarlo hasta la muerte. Debe pensar que una lealtad como ésa sólo puede interpretarse como la mejor forma posible de amor.

Sin embargo, Boscán dirige las coplas siguientes a una dama, seguramente distinta a las aludidas en los poemas anteriores, para hacerle saber «que ya no andaba en amores con ella». En esas coplas introduce una primera en que afirma que ha dejado de amarla por los «disfavores» recibidos, pero en las otras, las que envía a su amiga, reconoce la necesidad de dar a conocer su tormento para poder sentir vergüenza y así arrepentirse de haberla amado, pero no parece conseguirlo.

Después Boscán glosa la canción de Jorge Manrique «Justa fue mi perdición», incluida en el Cancionero general de 1511, no en las obras de amores del poeta castellano, sino en el apartado dedicado al género. En esas coplas el barcelonés, dentro de la más pura tradición autóctona, se muestra satisfecho de estar enamorado y se regodea de tal modo en el sufrimiento, que si siente pena por la que se va vuelve a estar alegre por la nueva que llega. Por eso se avergüenza de pedirle a su dama algún bien o galardón, porque cree que ya se lo ha dado haciéndolo sufrir de esa forma. 
En las coplas que incluye a continuación nuestro poeta siente esta vez la necesidad de contar cómo se ha enamorado o cómo se ha vuelto a enamorar, que no está claro a cuál de las dos situaciones se refiere. En determinados pasajes parece tener en cuenta la canción CCLXX y el soneto CCLXXI de Petrarca, y es en ese sentido en que puede estar recreando la segunda situación. En la canción el aretino se dirige a Amor para decirle que si quiere devolverlo a su yugo antiguo deberá primero resucitar a Laura y usar las mismas armas que había usado en el pasado, poniéndolas en su rostro y ojos, porque ésas son las armas más poderosas para vencer al corazón más duro:

Amor, se vuo' ch'i' torni al giogo anticho...

Ritogli a Morte quel ch'ella n'à tolto,

Et ripon' le tue insegne nel bel volto...

L'arme tue furon gli occhi...

Con quest'armi vincevi ogni cor duro (vv. 114-15, 76 y 89)

En el soneto, empieza confesando que sólo la muerte de la amada, después de veintiún años de estar preso, ha conseguido liberarlo del nudo de Amor, pero enseguida admite que Cupido, porque aún no quiere perderlo, ha encendido un nuevo fuego en su alma, fuego que también acaba apagando la muerte:

Non volendomi Amor perdere anchora,

Ebbe un altro lacciuol fra l'erba teso,

Et di nova ésca un altro foco acceso (vv. 5-7)

Tras unas estrofas iniciales refiriéndose a la decisión que ha tomado de confesar sus males, Boscán narra la manera en que se ha enamorado, no se sabe si por primera o enésima vez. Cuenta cómo de estar libre ha pasado a estar preso, y cómo Amor, no queriéndolo perder, puso sus armas en el rostro de su dama:

Yo me vi, sin ser cativo,

Muy suelto de cualquier pena,

Con el corazón esquivo,

Con el alma muy agena

Destos males en que vivo.

Libre'staba mi sentido,

Con poder para valerme;

Mas Amor, por no perderme,

Porque quedase perdido,

Anduvo por recogerme.

Si vuestra merced no fuera,

No hiciera el amor esto;

No me matara tan presto,

Señora, si no pusiera

Sus armas en vuestro gesto. (vv. 31-45) 
Incluso un poco más adelante tiene la debilidad de desear la muerte de la amada para conseguir olvidarla, pero inmediatamente se arrepiente de semejante deseo, considerándolo una herejía, porque no ha pretendido otra cosa sino matar y olvidar a su dios (vv. 111-120). Intenta olvidarla por otros medios, archiconocidos, como pensar en posibles defectos físicos que la dama pueda tener, pero ni aún por ésas logra su propósito, porque es incapaz de hallarlos, ni tan siquiera cuando no la tiene delante (vv. 201-210). En las coplas siguientes, Boscán vuelve a tratar el mismo tema que en las anteriores, pero narra su nuevo enamoramiento de modo distinto. Afirma que en el pasado estuvo enamorado y que Amor lo libró de ese sentimiento para hacerle experimentar otro que fuera mucho mayor:

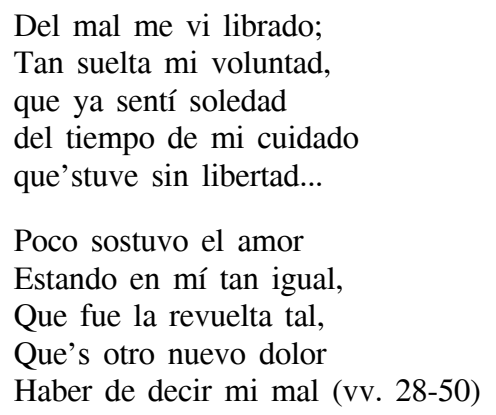

Para esa nostalgia («soledad») que siente del tiempo en que había estado preso por Amor sin duda que estuvo atento al soneto LXXXIX en que Petrarca, tras haber huido momentáneamente de Cupido, expresa la misma idea:

Donne mie, lungo fòra a ricontarve

Quanto la nova libertà m'increbbe.

Diceami il cor che per sé non saprebbe

Viver un giorno...

Onde più volte suspirando indietro

Dissi : Oimè, il giogo et le catene e i ceppi

Eran più dolci che l'andare sciolto (2-6 y 9-11)

En esta ocasión nuestro poeta no desea la muerte de la amada, sino la de sus rivales, pero se arrepiente de haberla deseado, porque teme que ella pueda acabar llorándolos. También busca maneras para olvidarla, pensando no tanto en sus defectos físicos, sino en humillaciones por las que le haya hecho pasar, pero tampoco las logra reconocer como tales.

Para el siguiente lugar Boscán elige unas coplas que seguramente fueron concebidas para abrir un pequeño cancionero dedicado a una de las damas de las que llegó a enamorarse. Las titula «Otras a su amiga enviándole un cancionero de sus coplas», y en sus veinte versos le deja claro que no sólo están de- 
dicadas a ella sino a otras amantes que tuvo en el pasado. Afirma haberse salvado por el nuevo amor, el de la dama a la que convierte en destinataria de su cancionero, dando a entender que al enamorarse de las otras mujeres no anduvo demasiado acertado. Sin embargo, confiesa que los males que sintió por culpa de todas ellas vienen a ser como prefiguraciones (los llama «figuras») de los actuales. Estas coplas podía haberlas situado al principio del libro I, porque no hacen sino resumir su contenido, pero, por otra parte, no marcan ninguno tipo de inflexión entre el presente y el pasado, al no introducir ninguna diferencia entre uno y otro período.

Después de los villancicos satíricos de diversos autores, a los que recurre para situar sus amores en un tiempo determinado, la primavera-verano de 1526, incluye dos canciones, la XXII y la XXIII, para en una ponderar su sufrimiento, diciendo que no lo siente como querría por miedo al que aún le queda por pasar, y en la otra para aclarar que no piensa nunca separarse de la amada, pero que si alguna vez lo hiciere que no merecería volver a verla.

En las coplas siguientes, en cambio, acusa a la dama de serle infiel en el transcurso de su ausencia, y si bien está dispuesto a perdonarla, dejando pasar el tiempo, no sabe si será capaz de olvidar semejante vileza. Por tal motivo duda sobre cómo reaccionar, si condenándola enérgicamente, buscando su arrepentimiento, o si perdonándola, comportándose como si no hubiera pasado nada. Si sigue la primera solución teme que pueda dolerle más su arrepentimiento que el daño que le haya causado por su infidelidad («que tenga yo por peor,/ para mí, vuestro remedio/ que, señora, mi dolor»); y si opta por la segunda salida se imagina a sus amigos tratándole de tonto y blando.

En las penúltimas coplas, vuelve a abordar el tema del enamoramiento, sin especificar si es uno nuevo o el primero, pero se presenta ya entregándose al amor porque acaba de ver a la amada («pues me hizo mi ventura/ que mirase vuestro gesto»). Sucumbe con facilidad, sin oponer resistencia, pero pronto busca el modo de alejarse, y cuando lo hace se da cuenta que siempre lleva consigo, en su pensamiento, a la amada (por eso dice que el lugar a donde va la halla a ella primero como si lo estuviera esperando). Intenta liberarse de amor, pero cuando más lo intenta más queda atrapado en sus redes («que’l trabajo que sostengo/ de soltarme más me prende»).

En la última canción, el poeta parece que se proponga regresar tras haberse marchado, y que tenga muchas ganas de regresar, pero enseguida admite que esas ganas son absurdas porque piensa que en realidad nunca se ha marchado, que siempre, a pesar de la separación física, ha estado con la amada al no poder olvidarla en ningún momento. Es por eso que al final parece plantearse que en lugar de regresar lo que tiene que hacer es marcharse de una vez por todas («¿Qué'sperar hay tan perdido [el de regresar],/ que’spere sino partir/ después de tan mal partido?»). 
En las últimas coplas Boscán podría estar ofreciendo una respuesta a la canción anterior, al reconocer que por fin ha conseguido marcharse de verdad del lugar en que se había enamorado (esto es, la corte del Emperador) y que en ese nuevo lugar ha podido empezar una nueva vida, después de haber roto definitivamente con el pasado. Pero en esas coplas, dirigidas al Almirante de Castilla, introduce un cambio con respecto a la historia amorosa narrada en las composiciones que las preceden. Es un cambio similar en la trascendencia al que sufre Petrarca tras la muerte de Laura.

\section{CONCLUSIÓN}

Boscán decide ordenar su libro I siguiendo sobre todo criterios cronológicos, porque narra a lo largo de sus poemas una historia de amor en la que introduce el cambio más importante al final para anunciar unos nuevos sentimientos que confesará ya consumados en los dos libros posteriores. La ordenación de ese primer libro prácticamente la tiene decidida en su primera versión, la que elabora hacia 1538, porque para la última versión, la que lleva a la imprenta en 1542, sólo añade un poema por el principio, al que asigna la función de initium narrationis. En las dos versiones, para cerrar el libro elige un poema que no es más que la respuesta que dio a otro que el Almirante de Castilla don Fadrique Enríquez le había dirigido preguntándole por unos amores que el destinatario había dejado en la corte. En ese poema final anticipa la transformación que experimenta a raíz de su relación con la que en un futuro bastante inmediato será su esposa, doña Ana Girón de Rebolledo, en compañía de la cual ya se lo imagina Garcilaso en una elegía, la II, compuesta en agosto de 1535. Pero en el poema en cuestión acaba suprimiendo dos estrofas para evitar cualquier tipo de contradicción con los sonetos proemios del libro II que escribe poco antes de entregar el original a la imprenta.

Para varios de los poemas del libro I nuestro poeta ha usado diferentes sonetos y canciones de los Rerum vulgarium fragmenta de Petrarca. La deuda más evidente con el poeta italiano la crítica la reconoció en las coplas que ocupan la parte central del volumen, las que comienzan «Las cosas de menos pruebas», pero el barcelonés añade por el final una similitud, la del águila y sus crías, que toma de un pasaje de la Farsalia de Lucano. También utiliza a Petrarca, pero en una medida mucho menor, en las coplas que sitúa inmediatamente a continuación: empieza las unas calcando los dos primeros versos de un soneto del Canzoniere, y termina las otras traduciendo el último verso de ese mismo soneto. Para los poemas en que se refiere a nuevos amores, después de haber dejado otros, se ha basado en la canción y soneto, CCLXX y CCLXXI, en que Petrarca anuncia el nuevo acoso de Cupido al morir Laura. 
Para los poemas iniciales de ese libro I Boscán ha echado mano de los cantos de tema amoroso de Ausiàs March que en la edición de Carlos Amorós, tanto la de 1543 como la de 1545, aparecen al principio y tienen la función de narrar el enamoramiento del poeta la primera vez. Para el segundo poema en concreto ha podido tener en cuenta el que en el Cancionero General de 1511 abre las obras de amor de Jorge Manrique, al dudar a través de la imagen del relámpago y el trueno si se enamoró después o antes de ver a la amada. Para esa imagen pudo haberse basado en la epístola de Dante al marqués de Malaspina, pero también en el soneto CXL en que Petrarca siente reavivar su fuego amoroso al volver a ver a Laura.

En la mayor parte de su libro el barcelonés ha optado por contar las veces que se enamoró y desenamoró, no de la misma dama, sino de varias, y para dar cuenta de ese vaivén de sentimientos le fue muy útil el que pone de manifiesto Petrarca a lo largo de todo el Canzoniere aunque casi siempre a propósito de la misma Laura, tanto en vida como muerta. Al final del libro, sin embargo, decide explicar cómo logró salir de ese laberinto de amores coincidiendo con su abandono de la corte y regreso a su Barcelona natal para comenzar un estilo nuevo de vida. Por eso de alguna manera en el libro I rinde un especial homenaje a esa corte a la que estuvo ligado hasta el año 1534 cuando ya estaba decidido a casarse con doña Ana Girón de Rebolledo y poner fin a su leyenda de amante mudable que le había acompañado hasta entonces. 